\title{
Serum glucose levels for predicting death in patients admitted to hospital for community acquired pneumonia: prospective cohort study
}

\author{
(C) $(\Theta)$ OPEN ACCESS
}

\begin{abstract}
Philipp M Lepper consultant physician ${ }^{1}$, Sebastian Ott consultant physician ${ }^{2}$, Eveline Nüesch statistician $^{34}$, Maximilian von Eynatten consultant physician ${ }^{5}$, Christian Schumann consultant physician $^{6}$, Mathias W Pletz professor ${ }^{7}$, Nicole M Mealing statistician ${ }^{34}$, Tobias Welte professor ${ }^{8}$, Torsten T Bauer professor ${ }^{9}$, Norbert Suttorp professor ${ }^{10}$, Peter Jüni professor ${ }^{34}$, Robert Bals professor $^{1}$, Gernot Rohde professor ${ }^{11}$, on behalf of the German Community Acquired Pneumonia Competence Network (CAPNETZ)
\end{abstract}

\begin{abstract}
${ }^{1}$ Department of Internal Medicine V, University Hospital of Saarland, D-66421, Homburg, Germany; ${ }^{2}$ Department of Pneumology, University Hospital of Bern (Inselspital) and University of Bern, Bern, Switzerland; ${ }^{3}$ Clinical Trials Unit, University Hospital of Bern (Inselspital) and University of Bern; ${ }^{4}$ Institute of Social and Preventive Medicine, University of Bern; ${ }^{5}$ Department of Diabetes, Endocrinology and Clinical Chemistry, University Hospital of Heidelberg, Heidelberg, Germany; ${ }^{6}$ Department of Internal Medicine II, University Hospital of Ulm, Ulm, Germany; ${ }^{7}$ Division of Gastroenterology, Hepatology and Infectious Diseases, Jena University Hospital, Jena, Germany; ${ }^{8}$ Department of Pneumology, Hannover Medical School, University of Hannover, Hannover, Germany; ${ }^{9}$ Department of Pneumology, Lungenklinik Heckeshorn, Klinikum Emil von Behring, Berlin, Germany; ${ }^{10}$ Department of Pneumology and Infectious Diseases, University Hospital of Berlin (Charité), Berlin, Germany; ${ }^{11}$ Department of Respiratory Medicine, Maastricht University Medical Center, Maastricht, Netherlands
\end{abstract}

\begin{abstract}
Objective To examine whether acute dysglycaemia predicts death in people admitted to hospital with community acquired pneumonia.

Design Multicentre prospective cohort study.

Setting Hospitals and private practices in Germany, Switzerland, and Austria.

Participants 6891 patients with community acquired pneumonia included in the German community acquired pneumonia competence network (CAPNETZ) study between 2003 and 2009.

Main outcome measures Univariable and multivariable hazard ratios adjusted for sex, age, current smoking status, severity of community acquired pneumonia using the CRB-65 score (confusion, respiratory rate $>30 / \mathrm{min}$, systolic blood pressure $\leq 90 \mathrm{~mm} \mathrm{Hg}$ or diastolic blood pressure $\leq 60 \mathrm{~mm} \mathrm{Hg}$, and age $\geq 65$ years), and various comorbidities for death at 28,90 , and 180 days according to serum glucose levels on admission.
\end{abstract}

Results An increased serum glucose level at admission to hospital in participants with community acquired pneumonia and no pre-existing diabetes was a predictor of death at 28 and 90 days. Compared with participants with normal serum glucose levels on admission, those with mild acute hyperglycaemia (serum glucose concentration 6-10.99 $\mathrm{mmol} / \mathrm{L}$ ) had a significantly increased risk of death at 90 days (1.56, $95 \%$ confidence interval 1.22 to $2.01 ; \mathrm{P}<0.001)$, and this risk increased to 2.37 (1.62 to $3.46 ; \mathrm{P}<0.001$ ) when serum glucose concentrations were $\geq 14 \mathrm{mmol} / \mathrm{L}$. In sensitivity analyses the predictive value of serum glucose levels on admission for death was confirmed at 28 days and 90 days. Patients with pre-existing diabetes had a significantly increased overall mortality compared with those without diabetes (crude hazard ratio $2.47,95 \%$ confidence interval 2.05 to 2.98 ; $P<0.001$ ). This outcome was not significantly affected by serum glucose levels on admission ( $P=0.18$ for interaction).

Conclusions Serum glucose levels on admission to hospital can predict death in patients with community acquired pneumonia without pre-existing diabetes. Acute hyperglycaemia may therefore identify patients in need of intensified care to reduce the risk of death from community acquired pneumonia. 


\section{Introduction}

Community acquired pneumonia, one of the leading infectious diseases in more economically developed countries, is associated with considerable morbidity and mortality. The pulmonary infection itself but also its associated, especially systemic, inflammatory response, playing a major part in these outcomes. ${ }^{1}$ Any condition that increases susceptibility to infection and predisposes to severe disease may have an impact on outcome. Diabetes mellitus is linked to impaired immunity and has to be considered a predisposing factor for a wide variety of infectious diseases, including pneumonia..$^{2-4} \mathrm{Up}$ to $25 \%$ of patients with community acquired pneumonia have diabetes. ${ }^{5}$ Above all, there is a clear association between diabetes and cardiovascular disease and stroke, both major contributors to complications of community acquired pneumonia. ${ }^{16-8}$ A plethora of diabetes associated conditions such as an increased risk of aspiration, decreased immunity, impaired lung function, and pulmonary microangiopathy, are assumed to link diabetes and community acquired pneumonia. ${ }^{9}$ It is plausible that chronic hyperglycaemia in itself influences a variety of host defence functions, such as chemotaxis, phagocytosis, and bactericidal activity of histiocytic cells. Nevertheless it has been shown that intensive insulin therapy to correct the metabolic status of patients admitted to hospital has no evident effect on infections or overall mortality. ${ }^{10}$

Recent, mainly retrospective studies, suggested that pre-existing diabetes or alterations to glucose serum levels are associated with an increased length of hospital stay or higher mortality due to infections, including community acquired pneumonia, but others showed no or no clear association. ${ }^{11-18}$ Some of the previous studies, showing an association between diabetes and admission to hospital, might be confounded by a high prevalence of underlying comorbidities and selective patient recruitment. ${ }^{13} 16$

Given the strong association between diabetes and

cardiovascular disease that contributes to overall mortality from community acquired pneumonia and infection and acute, illness related hyperglycaemia, we tested the hypothesis that glucose serum levels on admission and pre-existent diabetes are associated with mortality in patients admitted to hospital for community acquired pneumonia.

\section{Methods}

We carried out a multicentre study using prospective data from the German collaborative network on community acquired pneumonia (CAPNETZ). ${ }^{19}$ All participants gave informed consent. Data were collected based on a standard protocol, starting in July 2002, and analysed in December 2009. We included adults presenting with a new pulmonary infiltrate on a chest radiograph together with at least one symptom or sign of lower respiratory tract infection (fever, cough, purulent sputum, focal chest signs). Exclusion criteria were hospital admission within the past 28 days; immunosuppression, defined as chemotherapy or neutropenia $<1000 \mu \mathrm{L}$ during the past 28 days; treatment with more than $20 \mathrm{mg}$ corticosteroids daily for longer than 14 days; HIV infection; immunosuppressive therapy after organ or bone marrow transplantation; and active tuberculosis. Participants were followed up for six months.

Severity of pneumonia was assessed using the CRB-65 score (confusion, respiratory rate $>30 / \mathrm{min}$, systolic blood pressure $\leq 90 \mathrm{~mm} \mathrm{Hg}$ or diastolic blood pressure $\leq 60 \mathrm{~mm} \mathrm{Hg}$, and age $\geq 65$ years). ${ }^{20}$ The supplementary appendix provides a description of the study setting, periods of recruitment, eligibility criteria, follow-up, and mode of data collection.

\section{Definitions and measurement of glucose serum levels}

We assessed whether baseline diabetes status (ascertained on the basis of self report or drug use, including long term use of glucose lowering drugs, or a combination of both) and serum glucose levels on admission related to death from community acquired pneumonia within the first 28, 90, and 180 days from diagnosis. Single random glucose concentrations of $11.1 \mathrm{mmol} / \mathrm{L}$ $(200 \mathrm{mg} / \mathrm{dL})$ or less are formally within the "normal" range ${ }^{21}$; however, for our analysis we defined acute hyperglycaemia as any serum glucose concentration of $6 \mathrm{mmol} / \mathrm{L}$ or more measured on admission. Additionally, we a priori defined similar, or as in previous studies, ${ }^{2161722}$ categories for serum glucose concentration of $<4 \mathrm{mmol} / \mathrm{L}(72 \mathrm{mg} / \mathrm{dL}), 4-5.99 \mathrm{mmol} / \mathrm{L}(108$ $\mathrm{mg} / \mathrm{dL}), 6-10.99 \mathrm{mmol} / \mathrm{L}$ (198 mg/dL), 11-13.99 mmol/L (252 $\mathrm{mg} / \mathrm{dL})$, and $\geq 14 \mathrm{mmol} / \mathrm{L}(252 \mathrm{mg} / \mathrm{dL})$.

\section{Statistical analysis}

Using univariable Cox proportional hazards models, and deriving 95\% confidence intervals, we examined the associations between baseline characteristics of participants and death from any cause after 90 days and tested associations with two sided Wald tests.

We categorised serum glucose level on admission using prespecified thresholds corresponding to the patients' baseline serum glucose levels at the time of enrolment (that is, admission to hospital). To assess associations between serum glucose levels or diabetes status and mortality after 90 days we used Kaplan-Meier estimates, and to test for linear trends across serum glucose levels we used multivariable Cox proportional hazards models adjusted for sex, CRB-65 score, comorbidities, smoking, and infectious agent. We then stratified the analyses of associations between serum glucose levels and mortality after 90 days according to diabetes status. Finally, using

Kaplan-Meier estimates and in crude and adjusted Cox proportional hazards regression analyses we compared mortality after 90 days in participants without diabetes and low or normal serum glucose concentrations ( $<6 \mathrm{mmol} / \mathrm{L}$ ), those without diabetes and increased serum glucose concentrations $(\geq 6$ $\mathrm{mmol} / \mathrm{L}$ ), and those with diabetes. In all regression analyses we accounted for missing data on covariates by using multiple imputation, with overall mortality, log transformed survival time, sex, age, smoking, CRB-65 class, comorbidities, serum glucose levels, admission to hospital, and infectious agent as variables in the imputation model, thus creating 20 imputed datasets. ${ }^{23}$ We then carried out a case analysis of the 5231 ( $71 \%$ ) patients with complete data on outcomes and covariates and sensitivity analyses to examine associations between serum glucose levels or diabetes and mortality up to 28 days and up to 180 days using crude and adjusted Cox proportional hazards models. Then we stratified analyses according to severity of pneumonia using cut-off scores of 1 and 3 points on the CRB-65 to distinguish between mild, moderate, and severe pneumonia and carried out a test for interaction between trends across serum glucose levels and severity of pneumonia. Finally, we carried out landmark analyses with a landmark point at 28 days, with trends across serum glucose levels determined separately for 0 to 28 days and 29 to 90 days, and a test for interaction between trends across serum glucose levels and time (0 to 28 days $v 29$ to 90 days).

All $\mathrm{P}$ values and $95 \%$ confidence intervals are two sided. Statistical analyses were done with Stata version 11.2 (College Station, TX). 


\section{Results}

Between 2002 and 2009, 7400 patients with community acquired pneumonia were included in the German community acquired pneumonia competence network (CAPNETZ) registry. Of these, 509 were excluded because of missing information on death, leaving 6891 patients from 12 clinical centres throughout Germany for analysis (see supplementary figure 1). At the time of enrolment, 1114 (16.2\%) patients had a diagnosis of diabetes. The mean age of participants was 59.8 (SD 18.5) years and 3805 $(55.2 \%)$ were men. Table $1 \Downarrow$ provides an overview of the participants' baseline characteristics and the hazard ratios of death within 90 days of admission for community acquired pneumonia. In total, $4671(67.8 \%)$ participants were treated as inpatients.

\section{Admission hyperglycaemia and mortality}

Overall, 324 (4.7\%) participants died within 28 days, 514 (7.5\%) within 90 days, and 648 (9.4\%) within 180 days. Overall mortality on days 28,90 , and 180 was significantly higher in participants with diabetes than without diabetes (day 90: $14.5 \%$ $v 6.1 \%$; crude hazard ratio $2.47,95 \%$ confidence interval 2.05 to 2.98; $\mathrm{P}<0.001)$. Mortality increased according to CRB-65 score $(\mathrm{P}<0.001)$. Being male and having comorbidities were also associated with increased mortality within 90 days $(\mathrm{P}<0.001)$. Table 1 shows crude associations between mortality within 90 days and patient baseline characteristics.

Higher serum glucose levels were associated with increased mortality in all patients ( $\mathrm{P}$ for trend $<0.001$ ). Compared with patients with normal serum glucose concentrations (4-5.99 $\mathrm{mmol} / \mathrm{L}$ ), mortality within 90 days increased in a stepwise manner in those with glucose concentrations of 6-10.99 mmol/L (crude hazard ratio $2.89,95 \%$ confidence interval 2.27 to 3.69 ), $11-13.99 \mathrm{mmol} / \mathrm{L}$ (4.01, 2.78 to 5.81$)$, and $\geq 14 \mathrm{mmol} / \mathrm{L}(6.04$, 4.18 to 8.74$)$; fig $1 \Downarrow)$.

Participants without diabetes on admission showed a clear trend towards an increasing mortality after 90 days with higher than normal serum glucose levels on admission. This observation was highly significant ( $\mathrm{P}$ for trend $<0.001$; fig 1 ).

Participants without diabetes and normal serum glucose levels had the lowest mortality (3\%) after 90 days (fig $2 \Downarrow$ ), whereas the mortality rate in those without diabetes but with high serum glucose levels was 10\% (adjusted hazard ratio 1.72, 95\% confidence interval 1.33 to 2.23 ) and those with diabetes was $14 \%(1.88,1.42$ to 2.47$)$. Although the risk of mortality from community acquired pneumonia was significantly higher in patients with than without diabetes, the relation between glucose levels on admission and mortality was not significant in this cohort $(\mathrm{P}=0.18)$. Generally, low serum glucose levels $(<4$ $\mathrm{mmol} / \mathrm{L}$ ) were not associated with mortality in participants without diabetes (hazard ratio $0.68,95 \%$ confidence interval 0.33 to 1.42 ).

The association between hyperglycaemia on admission and mortality was also evident up to day 28. Participants with increased serum glucose levels on admission were more likely to die within the first 28 days after admission than those with normal serum glucose levels (adjusted $\mathrm{P}$ for trend $<0.001$ ). Supplementary table $1 \mathrm{~A}$ shows that participants with diabetes had a higher 28 day mortality than those without diabetes $(\mathrm{P}=0.042)$. Compared with participants with normal serum glucose levels and without pre-existing diabetes, the adjusted hazard ratio for death within 28 days after admission in those with diabetes was 1.92 (95\% confidence interval 1.34 to 2.75) and in those with hyperglycaemia without diabetes was 1.71
(1.22 to 2.40; $\mathrm{P}$ for trend 0.001). The same applied to 90 day mortality for the previously used cut-offs for increased fasting and the cut-offs for increased post-prandial serum glucose levels (see supplementary table 2 ). Table $2 \Downarrow$ summarises the multivariable hazard ratios of overall mortality in participants with and without diabetes. Analyses of mortality up to 28 days and up to 180 days showed the same associations with serum glucose levels as the main analyses of 90 day mortality (see supplementary tables $1 \mathrm{~A}-\mathrm{C}$ ).

\section{Mortality in participants with diabetes}

Estimates for the cumulative incidence of death within 90 days were significantly higher in participants with than without diabetes $(\mathrm{P}<0.001)$. After adjustment for baseline covariates, overall mortality was significantly higher in participants with diabetes (adjusted hazard ratio 1.26, 95\% confidence interval 1.04 to $1.54 ; \mathrm{P}=0.022$ ). The adjusted hazard ratio for mortality up to 28 days was 1.29 (95\% confidence interval 1.01 to 1.65 ; $\mathrm{P}<0.001$ ) and up to 180 days was 1.29 (1.08 to 1.54 , see supplementary tables $1 \mathrm{~A}-\mathrm{C})$. Figure $3 \Downarrow$ shows a higher mortality in participants with diabetes, regardless of serum glucose level on admission, and without diabetes with high serum glucose levels ( $\geq 6 \mathrm{mmol} / \mathrm{L}$ ) on admission. Increases in mortality appeared higher in participants with diabetes in crude analyses but of a similar magnitude in adjusted analyses.

\section{CRB-65 and serum glucose levels on admission}

In an analysis stratified according to CRB-65 score as a measure of pneumonia severity, serum glucose levels were associated with mortality in participants with a low CRB-65 score ( 0 points, see supplementary figure $3 \mathrm{~A}$ ) and moderate scores ( 1 or 2 points, see supplementary figure $3 \mathrm{~B}$ ), but not in those with high scores ( 3 or 4 points, see supplementary figure $3 \mathrm{C}$ ). Tests for interaction between trends across serum glucose levels and severity of pneumonia and association with serum glucose levels were borderline positive (see supplementary table 3 for the corresponding hazard ratios across serum glucose levels).

\section{Landmark analysis}

Supplementary table 4 and figure 4 present the results from landmark analyses with a cut-off at 28 days. The association of mortality with serum glucose levels was driven by short term mortality up to 28 days, with statistical trends observed for corresponding $\mathrm{P}$ values for interaction with time ( 0 to 28 days $v 29$ to 90 days).

\section{Examination of data missingness}

Overall, 509 of 7400 participants $(6.8 \%)$ were excluded from the analysis owing to missing information on vital status. Such participants tended to have a higher CRB- 65 score (36\% scored 0 or $1 v 72 \%$ in complete cases), and a higher proportion had diabetes $(26 \% v 16 \%)$, congestive heart failure (31\% v18\%), and cerebrovascular disease (35\% v 10\%) compared with those with complete information on mortality (see supplementary table 5). Among the remaining 6891 patients, 875 (12.7\%) had no information on serum glucose levels on admission and 21 $(0.3 \%)$ had no information on baseline diabetes status. Information on CRB-65 scores was missing for 749 participants (10.9\%). Thirty one participants had data missing on chronic respiratory tract disease, 39 on malignant tumour, 33 on chronic liver disease, 30 on congestive heart failure, 29 on cerebrovascular disease, 34 on chronic renal disease, and 163 on smoking status. Differences in missingness according to vital 
status were found for current smoking (64 (12\%) in participants who survived up to 90 days $v 99(1.6 \%)$ in participants who died) and for serum glucose levels (48 (9\%) v $827(13 \%)$, respectively). Participants with missing data on current smoking had higher CRB-65 scores $(\mathrm{P}<0.001)$ and a shorter survival time $(\mathrm{P}<0.001)$, whereas the opposite was found for serum glucose levels $(\mathrm{P}<0.001$ and $\mathrm{P}=0.046$, respectively). Complete datasets to assess the severity of community acquired pneumonia by calculating severity scores (CRB-65) were available for 6142 of the participants (89\%), and severity of community acquired pneumonia was distributed: $40 \%$ with 0 points, $41 \%$ with 1 point, $15.5 \%$ with 2 points, $3.2 \%$ with 3 points, and $0.3 \%$ with 4 points. Overall mortality on day 90 was $7.5 \%$.

In total, $5231(71 \%)$ participants had complete data on covariates. Supplementary table 6 compares these participants with those with incomplete data on covariates. Supplementary table 7 reports results of a complete case analysis in these 5231 participants.

\section{Discussion}

Mild to moderate hyperglycaemia on admission to hospital (serum glucose concentration 6-10.99 mmol/L; 108-198 mg/dL) has a major impact on mortality at 90 days in patients with community acquired pneumonia and pre-existing diabetes. We also found that patients with diabetes are at increased risk of death within 90 days regardless of their serum glucose levels on admission, and that most of the deaths occurred early and the association with glucose levels was driven by short term mortality up to 28 days. Our results suggest that acute dysregulation of glucose metabolism as well as longstanding diabetes have an impact on death from community acquired pneumonia.

A total of 1114 participants $(16.2 \%)$ in our population had pre-existing diabetes. This proportion of people with diabetes in a cohort of patients with community acquired pneumonia is in accordance with previous reports on comorbid conditions in such patients, reporting a prevalence of diabetes of $6-25 \%$. $^{25} 16$ In our cohort, hyperglycaemia was identified as an independent factor for increased risk of death from pneumonia. Our study shows that patients without known diabetes and mild to moderately increased serum glucose concentrations $(\geq 6.0$ $\mathrm{mmol} / \mathrm{L}$ ) are at an increased risk of death from pneumonia. Although a previous, noticeably smaller study could not detect effects on inhospital mortality at glucose concentrations greater than $6.11 \mathrm{mmol} / \mathrm{L}$ to $11.00 \mathrm{mmol} / \mathrm{L}$, and $14.00 \mathrm{mmol} / \mathrm{L}$ or more (higher odds ratio for inhospital mortality for patients with serum glucose concentrations between 11.01 and $13.99 \mathrm{mmol} / \mathrm{L}$; $\mathrm{P}=0.05),{ }^{17}$ our study is the first to show consistently significantly increased hazard ratios in a stepwise manner for mortality at three time points (days 28,90, and 180) and for serum glucose concentrations of $6.0 \mathrm{mmol} / \mathrm{L}$ or more.

When participants were stratified according to serum glucose levels on admission, there was a significant $(\mathrm{P}<0.001)$ and stepwise increasing difference in mortality. Again, in the cohort of participants presenting with baseline serum glucose concentrations of $6.0-10.99 \mathrm{mmol} / \mathrm{L}$ the hazard ratio was already 1.56 (95\% confidence interval 1.22 to $2.01 ; \mathrm{P}<0.001)$ and increased to 2.37 ( 1.62 to $3.46 ; \mathrm{P}<0.001$ ) in those with baseline serum glucose concentrations of $14.00 \mathrm{mmol} / \mathrm{L}$ or more. We analysed the influence of diabetes on 90 day mortality and found almost a twofold increase in mortality in participants with pre-existing diabetes (adjusted hazard ratio 1.88; $\mathrm{P}<0.001$ ).

Hyperglycaemia was associated with mortality in the overall analysis. In an exploratory analysis stratified according to severity of pneumonia using the CRB-65 score, we found associations of serum glucose levels with mortality to be robust for patients with mild or moderate pneumonia (CRB-65 score $\leq 2$ ) but not for patients with severe pneumonia. Tests for interaction of borderline significance suggested that this variation with severity of pneumonia was over and above that expected by chance alone. There was little evidence to suggest that serum glucose level on admission was associated with mortality in patients with pre-existing diabetes. Serum glucose concentrations below $4 \mathrm{mmol} / \mathrm{L}(72 \mathrm{mg} / \mathrm{dL})$ were not associated with increased mortality.

\section{Strengths and weaknesses of the study}

Our study has a prospective design and is possibly the largest cohort on community acquired pneumonia worldwide. This multicentre cohort study in different centres throughout Germany, Switzerland, and Austria, used a highly standardised reporting system and databank. For this study, private practices as well as large tertiary referral centres specialised in the treatment of respiratory tract disorders cooperated closely in patient recruitment. Thus we believe our cohort to be representative of patients with community acquired pneumonia in more economically developed countries. Other studies on glycaemia in patients with community acquired pneumonia used data from patient records in a retrospective manner or derived the diagnosis of community acquired pneumonia from International Classification of Diseases coding, which might have resulted in bias. ${ }^{2} 1625$

Our study has several limitations. Firstly, we did not establish a causal relation between serum glucose levels on admission and mortality. It is conceivable that hyperglycaemia is associated with increased mortality, but it is also conceivable that a common factor is related to both hyperglycaemia and increased mortality.

Secondly, there was no structured protocol describing treatment modalities for patients with increased serum glucose levels, and treatment was left to the discretion of the doctor in charge. Hence we were not able to examine changes in serum glucose levels during admission to hospital in a standardised fashion. This might bias results in any direction as we do not know if correction of increased serum glucose levels in community acquired pneumonia is relevant, and if correction is time sensitive. A decade ago, data from surgical patients in intensive care suggested that tight control of glycaemia contributes to a better outcome. ${ }^{26}$ However, the same group found that for medical patients this was true only for selected individuals. Unfortunately, these patients could not be identified before treatment. ${ }^{27}$ As of today, there is compelling evidence that tight glycaemic control at least in patients with sepsis has no benefit ${ }^{28}{ }^{29}$ as mortality remains unchanged and patients are at risk of sustaining relevant hypoglycaemia. ${ }^{30-32}$ Definite recommendations on serum glucose levels are lacking.

Additionally, glucocorticoids administered in the initial, acute phase of community acquired pneumonia were not recorded in our study and therefore could not be accounted for in the analysis. However, the use of glucocorticoids in community acquired pneumonia is discouraged in current guidelines and was likely to be low in our study. Continued therapy with corticosteroids of more than $20 \mathrm{mg}$ daily for longer than 14 days was an exclusion criterion.

Thirdly, although diabetes itself is clearly defined, we faced the problem of identifying participants with undiagnosed diabetes and those with stress related hyperglycaemia. Determination of glycated haemoglobin $\left(\mathrm{HbA}_{1 \mathrm{c}}\right)$ level on admission could have 
solved this problem only in part, as $\mathrm{HbA}_{1 \mathrm{c}}$ tests and their interpretation were not standardised before 2009. Since 2009, $\mathrm{HbA}_{\mathrm{lc}}$ testing has been recommended for the diagnosis of type 2 diabetes. ${ }^{33}$ Recent studies on community acquired pneumonia reported a prevalence of diabetes of 6-25\%, which is in the range of the prevalence of $16 \%$ in our cohort. ${ }^{251635}$ As we were unable to formally determine the robustness of results for a more reliable diagnosis of diabetes by laboratory tests, we cannot exclude the fact that some patients were misclassified. However, in a recent cohort study of patients with critical illness, ${ }^{36}$ only about $3 \%$ of those with increased serum glucose levels on admission were diagnosed as having type 2 diabetes during the first two years after critical illness. Assuming an equally low extent of diagnostic reclassification of patients through the use of additional laboratory tests in our study, we deem it unlikely that misclassification had an important impact on our results. The clinical definition of diabetes (self report, drug use, including long term use of glucose lowering drugs, or a combination of both), similar to that used by the Emerging Risk Factors Collaboration, ${ }^{3}$ seemed the most feasible approach in our setting given the uncertainties associated with the diagnosis of type 2 diabetes in patients with acute infection.

Finally, we had to exclude 509 of the 7400 patients $(6.8 \%)$ owing to missing information on vital status. Such patients tended to have a higher CRB-65 score and a higher proportion had diabetes, congestive heart failure, or cerebrovascular disease at baseline compared with those with complete information. These differences may have led to bias in both directions, towards an overestimation or underestimation of the association of serum glucose levels with mortality. In addition, information on serum glucose levels on admission was lacking in $12.6 \%$ of patients and we attempted to account for this by using multiple imputation. Multiple imputation yields valid results under the condition that there are no systematic differences between the missing values and the observed values (missing completely at random) or if systematic differences between missing and observed values can be explained by differences in observed data (missing at random). ${ }^{24}$ Observed patterns of data missingness, their association with baseline characteristics and mortality, and the inclusion of all relevant baseline covariates and variables of vital status in our imputation model make the missing at random assumption plausible. ${ }^{24}$ Results from complete case analyses and multiple imputation were similar, with associations being somewhat more conservative after multiple imputation. Furthermore, we found evidence for differences in missingness according to mortality for smoking status and serum glucose levels. Since we included mortality variables in the imputation model, this is unlikely to have invalidated our results. Additional limitations include potential residual confounding despite adjustment, and the possibility of a type II error in participants with diabetes: the number of such participants may have been too low to detect an association of serum glucose levels with mortality in this subgroup.

\section{Comparison with other studies}

The CAPNETZ cohort includes outpatients and a greater proportion of patients with mild pneumonia than does other cohorts. The mean age of patients in the present cohort was 60 years, which is lower than in most other cohorts on community acquired pneumonia. Furthermore, the admission rate to intensive care was relatively low, again reflecting a high proportion of mild cases. As severe hypoglycaemia tends to occur in patients who are critically ill, this may explain the lack of association of hypoglycaemia with mortality in our study compared with other studies. ${ }^{25} 37$
In line with our findings, data from a small trial in a veteran population with pneumococcal pneumonia suggest that hyperglycaemia is associated with greater disease severity and a worse outcome in patients without diabetes; however, this finding could not be extended to people with diabetes. ${ }^{18}$

Our results are consistent with and extend the findings of another retrospective analysis of unselected inpatients. ${ }^{38}$ In this study, groups were stratified according to whether participants had normoglycaemia, pre-existing diabetes, or newly diagnosed hyperglycaemia (fasting serum glucose concentration $>7 \mathrm{mmol} / \mathrm{L}$ or random serum glucose concentration $>11.1 \mathrm{mmol} / \mathrm{L}$ on two separate occasions). Compared with patients with normoglycaemia, after adjustment for important confounding factors, mortality was almost 20 times higher in patients with newly diagnosed hyperglycaemia $(\mathrm{P}<0.05)$, but only 2.7 times higher in those with known diabetes $(\mathrm{P}<0.05)$. As in the present study, it was not possible to distinguish between new onset diabetes and transient stress hyperglycaemia. ${ }^{38}$ The higher mortality observed in patients with community acquired pneumonia with diabetes may be due to the worsening of pre-existing cardiovascular disease or higher risk of acute kidney injury, thus a result of comorbidities that are more likely to be present in patients with longstanding diabetes. Patients with diabetes might in part be protected from acute glucose toxicity. ${ }^{39} 40$

\section{Additionally, our results support data from two Danish} population based studies. ${ }^{216}$ The first study reported a higher risk of hospital admission in hyperglycaemic patients with community acquired pneumonia and diabetes. ${ }^{2}$ Unfortunately the effects in patients without diabetes were not assessed. A second study from the same group found a higher mortality in hyperglycaemic patients without diabetes at 30 days. ${ }^{16}$

Our findings are in contrast with those of a recent study, which found that serum glucose levels on admission were associated with neither an increased risk of mortality at 90 days or death at one year. ${ }^{12}$ However, the authors concluded that increased serum glucose levels on admission might be harmful, as their estimate of 90 day mortality associated with the highest dysglycaemic category was non-significantly increased. We assume the sample size of this study to be too small to detect significant differences between groups.

\section{Explanations}

In the past, stress hyperglycaemia was often thought to be a useful adaptive response, glucose being a ready source of fuel for brain, skeletal muscle, heart, and other organs at a time of increased metabolic demand. Our results show that hyperglycaemia on admission in patients with community acquired pneumonia is associated with an adverse outcome and predicts mortality. This is the largest prospective cohort trial in patients with community acquired pneumonia on this topic, supporting and extending data from previous, smaller studies or retrospective, population based observational studies that showed an association of hyperglycaemia on admission with adverse events in the course of disease. ${ }^{211} 1314161725$ Our data clearly show by severity adjusted multivariate analysis that increased serum glucose levels at admission is a risk factor for increased risk of mortality in patients with community acquired pneumonia and that mortality starts to increase when serum glucose levels are slightly increased but remain below the defined threshold for overt diabetes. 


\section{Conclusions and clinical implications}

From our data we assume that patients with increased serum glucose levels or diabetes at the time community acquired pneumonia is diagnosed are at significantly increased risk of death from the disease. Oral glucose tolerance test and close glucose monitoring after discharge are necessary to diagnose overt diabetes and to prevent subacute or long term complications. Large scale trials are needed to define optimal serum glucose levels and to determine if a drug intervention is suitable to reduce mortality in patients with community acquired pneumonia. A focus on patients with a CRB-65 score of 2 or less seems most promising, as the evidence for an association of serum glucose levels with mortality was particularly robust in these patients.

We thank the clinical doctors and doctors in private practice who saw and identified patients with community acquired pneumonia for their work dedicated to CAPNETZ; the CAPNETZ study team either temporarily or permanently involved in patient recruitment and sample and data handling; and the patients included in the CAPNETZ study. See supplementary file for members of the CAPNETZ study group. Contributors: PML contributed to the conception and design of this particular CAPNETZ substudy, was involved in data analysis and interpretation, and drafted the manuscript. SO contributed to the conception and design of this particular CAPNETZ sub-study, was involved in data analysis and interpretation, and revised the manuscript critically for important intellectual content. PML and SO contributed equally to the manuscript. EN was involved in data analysis and interpretation, drafted the figures and tables, and revised the manuscript critically for important intellectual content. MvE contributed to the conception and design of this particular CAPNETZ substudy, was involved in data analysis and interpretation, and revised the manuscript critically for important intellectual content. CS and MWP were involved in data analysis and interpretation and revised the manuscript critically for important intellectual content. NMM did the statistical analysis for the revised version of the manuscript and revised the manuscript critically for important intellectual content.TW and NS were involved in data analysis and interpretation, revised the manuscript critically for important intellectual content, and contributed to the conception and design of the ongoing CAPNETZ study. TTB contributed to the conception and design of this particular CAPNETZ substudy, was involved in data interpretation, and revised the manuscript critically for important intellectual content. PJ contributed to the conception and design of this particular CAPNETZ study and revised the manuscript critically for important intellectual content. RB and GR were involved in data analysis and interpretation and revised the manuscript critically for important intellectual content. All authors approved the final version of the manuscript. PML is the guarantor.

Funding: CAPNETZ is funded by the German Ministry of Education and Research, BundesministeriumfürBildung und Forschung (grant No 01KI07145).

Competing interests: All authors have completed the ICMJE uniform disclosure form at www.icmje.org/coi_disclosure.pdf (available on request from the corresponding author) and declare: no support from any organisation for the submitted work; no financial relationships with any organisations that might have an interest in the submitted work in the previous three years; and no other relationships or activities that could appear to have influenced the submitted work.

Ethical approval: This study was approved by the institutional review board of the Otto-von-Guericke University, Magdeburg, Germany $(104 / 01)$ in 2001.

Data sharing: No additional data available.
1 Aliberti S, Amir A, Peyrani P, Mirsaeidi M, Allen M, Moffett BK, et al. Incidence, etiology, timing, and risk factors for clinical failure in hospitalized patients with community-acquired pneumonia. Chest 2008;134:955-62.

2 Kornum JB, Thomsen RW, Riis A, Lervang HH, Schonheyder HC, Sorensen HT. Diabetes, glycemic control, and risk of hospitalization with pneumonia: a population-based case-control study. Diabetes Care 2008;31:1541-5.

3 Seshasai SR, Kaptoge S, Thompson A, Di AE, Gao P, Sarwar N, et al. Diabetes mellitus, fasting glucose, and risk of cause-specific death. N Engl J Med 2011;364:829-41.

4 Shah BR, Hux JE. Quantifying the risk of infectious diseases for people with diabetes. Diabetes Care 2003;26:510-3

5 Abourizk NN, Vora CK, Verma PK. Inpatient diabetology. The new frontier. J Gen Intern Med 2004;19(5 Pt 1):466-71.

6 Ramirez J, Aliberti S, Mirsaeidi M, Peyrani P, Filardo G, Amir A, et al. Acute myocardia infarction in hospitalized patients with community-acquired pneumonia. Clin Infect Dis 2008;47:182-7.

7 Schramm TK, Gislason GH, Kober L, Rasmussen S, Rasmussen JN, Abildstrom SZ, et al. Diabetes patients requiring glucose-lowering therapy and nondiabetics with a prior myocardial infarction carry the same cardiovascular risk: a population study of 3.3 million people. Circulation 2008;117:1945-54.

8 Spencer EA, Pirie KL, Stevens RJ, Beral V, Brown A, Liu B, et al. Diabetes and modifiable risk factors for cardiovascular disease: the prospective Million Women Study. Eur J Epidemiol 2008;23:793-9.

9 Koziel H, Koziel MJ. Pulmonary complications of diabetes mellitus. Pneumonia. Infect Dis Clin North Am 1995;9:65-96.

10 Kansagara D, Fu R, Freeman M, Wolf F, Helfand M. Intensive insulin therapy in hospitalized patients: a systematic review. Ann Intern Med 2011;154:268-82.

11 Akbar DH. Bacterial pneumonia: comparison between diabetics and non-diabetics. Acta Diabetol 2001;38:77-82.

12 Eurich DT, Gamble JM, Marrie TJ, Majumdar SR. Dysglycaemia and 90 day and 1 year risks of death or readmission in patients hospitalised for community-acquired pneumonia. Diabetologia 2010;53:497-503.

13 Falguera M, Pifarre R, Martin A, Sheikh A, Moreno A. Etiology and outcome of community-acquired pneumonia in patients with diabetes mellitus. Chest 2005;128:3233-9.

14 Fine MJ, Auble TE, Yealy DM, Hanusa BH, Weissfeld LA, Singer DE, et al. A prediction rule to identify low-risk patients with community-acquired pneumonia. N Engl J Med 1997;336:243-50

15 Kaplan V, Angus DC, Griffin MF, Clermont G, Scott WR, Linde-Zwirble WT. Hospitalized community-acquired pneumonia in the elderly: age- and sex-related patterns of care and outcome in the United States. Am J Respir Crit Care Med 2002;165:766-72.

16 Kornum JB, Thomsen RW, Riis A, Lervang HH, Schonheyder HC, Sorensen HT. Type 2 diabetes and pneumonia outcomes: a population-based cohort study. Diabetes Care 2007;30:2251-7.

17 McAlister FA, Majumdar SR, Blitz S, Rowe BH, Romney J, Marrie TJ. The relation between hyperglycemia and outcomes in 2,471 patients admitted to the hospital with community-acquired pneumonia. Diabetes Care 2005:28:810-5.

18 Rueda AM, Ormond M, Gore M, Matloobi M, Giordano TP, Musher DM. Hyperglycemia in diabetics and non-diabetics: effect on the risk for and severity of pneumococcal pneumonia. $J$ Infect 2010;60:99-105.

19 Welte T, Suttorp N, Marre R. CAPNETZ-community-acquired pneumonia competence network. Infection 2004;32:234-8.

20 Bauer TT, Ewig S, Marre R, Suttorp N, Welte T. CRB-65 predicts death from community-acquired pneumonia. J Intern Med 2006;260:93-101.

21 Genuth S, Alberti KG, Bennett P, Buse J, Defronzo R, Kahn R, et al. Follow-up report on the diagnosis of diabetes mellitus. Diabetes Care 2003;26:3160-7.

22 Kosiborod M, Inzucchi SE, Krumholz HM, Xiao L, Jones PG, Fiske S, et al. Glucometrics in patients hospitalized with acute myocardial infarction: defining the optimal outcomes-based measure of risk. Circulation 2008;117:1018-27.

23 Royston P. Multiple imputation of missing values. Stata J 2004;4:227-41.

24 Sterne JA, White IR, Carlin JB, Spratt M, Royston P, Kenward MG, et al. Multiple imputation for missing data in epidemiological and clinical research: potential and pitfalls. $B M J$ 2009;338:b2393.

25 Godar DA, Kumar DR, Schmelzer KM, Talsness SR, Liang H, Schmelzer JR, et al. The impact of serum glucose on clinical outcomes in patients hospitalized with community-acquired pneumonia. WMJ 2011;110:14-20.

26 Van den Berghe G, Wouters P, Weekers F, Verwaest C, Bruyninckx F, Schetz M, et al. Intensive insulin therapy in the critically ill patients. N Engl J Med 2001;345:1359-67.

27 Van den Berghe G, Wilmer A, Hermans G, Meersseman W, Wouters PJ, Milants I, et al. Intensive insulin therapy in the medical ICU. N Engl J Med 2006;354:449-61.

28 Brunkhorst FM, Engel C, Bloos F, Meier-Hellmann A, Ragaller M, Weiler N, et al. Intensive insulin therapy and pentastarch resuscitation in severe sepsis. N Engl J Med 2008;358:125-39.

29 Marik PE, Preiser JC. Toward understanding tight glycemic control in the ICU: a systematic review and metaanalysis. Chest 2010;137:544-51.

30 Finfer S, Chittock DR, Su SY, Blair D, Foster D, Dhingra V, et al. Intensive versus conventional glucose control in critically ill patients. N Engl J Med 2009;360:1283-97.

31 Griesdale DE, de Souza RJ, van Dam RM, Heyland DK, Cook DJ, Malhotra A, et al. Intensive insulin therapy and mortality among critically ill patients: a meta-analysis including NICE-SUGAR study data. CMAJ 2009;180:821-7.

32 Wiener RS, Wiener DC, Larson RJ. Benefits and risks of tight glucose control in critically ill adults: a meta-analysis. JAMA 2008;300:933-44.

33 American Diabetes Association. Diagnosis and classification of diabetes mellitus. Diabetes Care 2010;33(suppl 1):S62-9.

34 International Expert Committee report on the role of the A1C assay in the diagnosis of diabetes. Diabetes Care 2009;32:1327-34.

35 Centers for Disease Control and Prevention. National diabetes fact sheet: general information and national estimates on diabetes in the United States, 2005. Department of Health and Human Services, Centers for Disease Control and Prevention, 2005.

36 Gornik I, Vujaklija-Brajkovic A, Renar IP, Gasparovic V. A prospective observational study of the relationship of critical illness associated hyperglycaemia in medical ICU patients and subsequent development of type 2 diabetes. Crit Care 2010;14:R130.

37 Singanayagam A, Chalmers JD, Hill AT. Admission hypoglycaemia is associated with adverse outcome in community-acquired pneumonia. Eur Respir J 2009;34:932-9.

38 Umpierrez GE, Isaacs SD, Bazargan N, You X, Thaler LM, Kitabchi AE. Hyperglycemia: an independent marker of in-hospital mortality in patients with undiagnosed diabetes. $J$ Clin Endocrinol Metab 2002;87:978-82. 


\section{What is already known on this topic}

One of the leading infectious diseases in more economically developed countries, community acquired pneumonia, is associated with considerable morbidity and mortality

Hyperglycaemia is a risk factor for premature death from different causes, including infectious diseases

Previous, mainly small and retrospective studies found an association between hyperglycaemia and death from community acquired pneumonia

\section{What this study adds}

Mild to moderate hyperglycaemia on admission to hospital has a major impact on mortality in patients with community acquired pneumonia and previously undiagnosed diabetes

Patients with diabetes are at increased risk of death regardless of serum glucose levels on admission

Acute dysregulation of glucose metabolism as well as longstanding diabetes may have an impact on mortality in patients with community acquired pneumonia

39

Vanhorebeek I, Van den Berghe G. Diabetes of injury: novel insights. Endocrinol Metab Clin North Am 2006;35:859-72, x.

40 Vanhorebeek I, Gunst J, Derde S, Derese I, Boussemaere M, Guiza F, et al. Insufficient activation of autophagy allows cellular damage to accumulate in critically ill patients. $J$ Clin Endocrinol Metab 2011;96:E633-45.

Accepted: 17 April 2012

\section{Cite this as: BMJ 2012;344:e3397}

This is an open-access article distributed under the terms of the Creative Commons Attribution Non-commercial License, which permits use, distribution, and reproduction in any medium, provided the original work is properly cited, the use is non commercial and is otherwise in compliance with the license. See: http://creativecommons.org/licenses/bync/2.0/ and http://creativecommons.org/licenses/by-nc/2.0/legalcode. 


\section{Tables}

Table 1| Baseline characteristics in 6891 patients with community acquired pneumonia and hazard ratio for death within 90 days after admission to hospital

\begin{tabular}{|c|c|c|c|c|c|c|}
\hline \multirow[b]{2}{*}{ Characteristics } & \multicolumn{2}{|c|}{ Follow-up at 90 days } & \multirow[b]{2}{*}{$\begin{array}{l}\text { Hazard ratio* }(95 \% \mathrm{Cl}) \text { for } \\
\text { complete data }\end{array}$} & \multirow[b]{2}{*}{$P$ value } & \multirow{2}{*}{$\begin{array}{c}\text { Hazard ratio* }(95 \% \mathrm{Cl}) \\
\text { using multiple } \\
\text { imputation } \dagger\end{array}$} & \multirow[b]{2}{*}{$P$ value $\neq$} \\
\hline & $\begin{array}{l}\text { No (\%) who died } \\
(n=514)\end{array}$ & No $(\%)$ alive $(n=6377)$ & & & & \\
\hline \multicolumn{7}{|l|}{ Sex: } \\
\hline Women & $193(38)$ & $2893(45)$ & 1.00 (ref) & \multirow[t]{2}{*}{0.001} & 1.00 (ref) & \multirow[t]{2}{*}{0.001} \\
\hline Men & $321(62)$ & $3484(55)$ & 0.74 (0.62 to 0.88$)$ & & 0.74 (0.62 to 0.88$)$ & \\
\hline \multicolumn{7}{|l|}{ CRB-65\$: } \\
\hline 0 & $28(5)$ & $2433(38)$ & 1.00 (ref) & \multirow[t]{5}{*}{$<0.001$} & 1.00 (ref) & \multirow[t]{5}{*}{$<0.001$} \\
\hline 1 & $178(35)$ & $2335(37)$ & 6.38 (4.28 to 9.50$)$ & & 6.35 (4.32 to 9.33 ) & \\
\hline 2 & $164(32)$ & $786(12)$ & 16.64 (11.14 to 24.84$)$ & & 17.25 (11.68 to 25.48 ) & \\
\hline 3 & $63(12)$ & $132(2)$ & 35.40 (22.66 to 55.21$)$ & & 37.84 (24.77 to 57.81 ) & \\
\hline 4 & $15(3)$ & $8(0)$ & 100.64 (53.71 to 188.58 ) & & 96.71 (52.29 to 178.88$)$ & \\
\hline \multicolumn{7}{|c|}{$\begin{array}{l}\text { Serum glucose } \\
\text { concentration (mmo//L): }\end{array}$} \\
\hline$<4$ & $17(3)$ & $467(7)$ & 0.94 (0.56 to 1.58$)$ & \multirow[t]{5}{*}{$<0.001$} & 0.83 (0.49 to 1.39$)$ & \multirow[t]{5}{*}{$<0.001$} \\
\hline $4-5.99$ & $84(16)$ & $2160(34)$ & 1.00 (ref) & & 1.00 (ref) & \\
\hline 6-10.99 & $281(55)$ & 2487 (39) & 2.80 (2.19 to 3.57 ) & & 2.89 (2.27 to 3.69$)$ & \\
\hline $11-13.99$ & $41(8)$ & $262(4)$ & 3.82 (2.63 to 5.55 ) & & 4.01 (2.78 to 5.81 ) & \\
\hline$\geq 14$ & $43(8)$ & $174(3)$ & 5.91 (4.10 to 8.54$)$ & & 6.04 (4.18 to 8.74$)$ & \\
\hline \multicolumn{7}{|l|}{ Diabetes mellitus: } \\
\hline No & $351(69)$ & $5405(85)$ & 1.00 (ref) & \multirow[t]{2}{*}{$<0.001$} & 1.00 (ref) & \multirow[t]{2}{*}{$<0.001$} \\
\hline Yes & $161(31)$ & $953(15)$ & 2.48 (2.05 to 2.99 ) & & 2.47 (2.05 to 2.98$)$ & \\
\hline \multicolumn{7}{|c|}{$\begin{array}{l}\text { Chronic respiratory tract } \\
\text { disease: }\end{array}$} \\
\hline No & $306(60)$ & $4088(65)$ & 1.00 (ref) & \multirow[t]{2}{*}{0.058} & 1.00 (ref) & \multirow[t]{2}{*}{0.053} \\
\hline Yes & $203(40)$ & $2263(35)$ & 1.19 (0.99 to 1.42$)$ & & $1.19(1.00$ to 1.42$)$ & \\
\hline \multicolumn{7}{|l|}{ Malignant tumour: } \\
\hline No & $411(82)$ & $5793(91)$ & 1.00 (ref) & \multirow[t]{2}{*}{$<0.001$} & 1.00 (ref) & \multirow[t]{2}{*}{$<0.001$} \\
\hline Yes & $95(18)$ & $552(9)$ & 2.29 (1.83 to 2.87$)$ & & 2.29 (1.84 to 2.87$)$ & \\
\hline \multicolumn{7}{|c|}{ Chronic liver disease: } \\
\hline No & $482(94)$ & $6162(97)$ & 1.00 (ref) & $<0.001$ & 1.00 (ref) & $<0.001$ \\
\hline Yes & $29(6)$ & $185(3)$ & 1.96 (1.35 to 2.85$)$ & & 1.97 (1.36 to 2.87$)$ & \\
\hline Congestive heart & & & & & & \\
\hline No & $280(55)$ & $5316(84)$ & 1.00 (ref) & $<0.001$ & 1.00 (ref) & $<0.001$ \\
\hline Yes & $230(45)$ & $1035(16)$ & 3.94 (3.31 to 4.69 ) & & 3.95 (3.32 to 4.70$)$ & \\
\hline Cerebrovascular d & & & & & & \\
\hline No & $326(64)$ & $5814(92)$ & 1.00 (ref) & $<0.001$ & 1.00 (ref) & $<0.001$ \\
\hline Yes & $184(36)$ & $538(8)$ & 5.39 (4.50 to 6.46$)$ & & 5.40 (4.51 to 6.47$)$ & \\
\hline Chronic renal dise & & & & & & \\
\hline No & $379(75)$ & $5912(93)$ & 1.00 (ref) & $<0.001$ & 1.00 (ref) & $<0.001$ \\
\hline Yes & $130(25)$ & $436(7)$ & 4.18 (3.43 to 5.10$)$ & & 4.18 (3.43 to 5.10$)$ & \\
\hline Current smoking: & & & & & & \\
\hline No & $363(81)$ & $4293(68)$ & 1.00 (ref) & $<0.001$ & 1.00 (ref) & $<0.001$ \\
\hline Yes & $87(19)$ & $1985(32)$ & 1.89 (1.49 to 2.39 ) & & 1.86 (1.47 to 2.35$)$ & \\
\hline
\end{tabular}

749 patients (11\%) had missing information on CRB-65 score, 875 (13\%) on glucose levels, $21(0.3 \%)$ on diabetes, $31(0.5 \%)$ on chronic respiratory tract disease, $39(0.6 \%)$ on malignant tumour, $33(0.5 \%)$ on chronic liver disease, $30(0.4 \%)$ on congestive heart failure, $29(0.4 \%)$ on cerebrovascular disease, $34(0.5 \%)$ on chronic renal disease, and $163(2 \%)$ on current smoking. 
Table 1 (continued)

\begin{tabular}{|c|c|c|c|c|}
\hline \multirow[b]{2}{*}{ Characteristics } & \multicolumn{2}{|c|}{ Follow-up at 90 days } & \multirow[b]{2}{*}{$\begin{array}{c}\text { Hazard ratio* }(95 \% \mathrm{Cl}) \text { for } \\
\text { complete data }\end{array}$} & \multirow{2}{*}{$\begin{array}{c}\text { Hazard ratio* }(95 \% \mathrm{Cl}) \\
\text { using multiple } \\
\text { imputation† }\end{array}$} \\
\hline & $\begin{array}{c}\text { No }(\%) \text { who died } \\
(n=514)\end{array}$ & No $(\%)$ alive $(n=6377)$ & & \\
\hline
\end{tabular}

*From univariable Cox proportional hazards models. Hazard ratios larger than 1 indicate a lower mortality in the reference category.

†Multiple imputation of missing covariate data, including all 6891 participants.

‡Derived from two sided Wald tests.

$\S$ Score for confusion, respiratory rate $>30 / \mathrm{min}$, systolic blood pressure $\leq 90 \mathrm{~mm} \mathrm{Hg}$ or diastolic blood pressure $\leq 60 \mathrm{~mm} \mathrm{Hg}$, and age $\geq 65$ years 


\begin{tabular}{|c|c|c|c|c|c|}
\hline \multirow[b]{2}{*}{ Variables } & \multicolumn{2}{|c|}{ No/Total No (\%) } & \multicolumn{2}{|c|}{ Hazard ratio* $(95 \% \mathrm{Cl})$} & \multirow[b]{2}{*}{$\mathbf{P}$ value } \\
\hline & Diabetes $(n=1114)$ & No diabetes $(n=5756)$ & Diabetes & No diabetes & \\
\hline \multicolumn{6}{|l|}{ Sex: } \\
\hline Women & $76 / 446(17)$ & $172 / 2629(7)$ & 1.00 (ref) & 1.00 (ref) & \multirow[t]{2}{*}{0.60} \\
\hline Men & $133 / 668(20)$ & $307 / 3127(10)$ & 0.97 (0.70 to 1.35$)$ & 0.79 (0.63 to 0.99$)$ & \\
\hline \multicolumn{6}{|c|}{ CRB-65 scoreł: } \\
\hline 0 & 4/176 (2) & 44/2281 (2) & 1.00 (ref) & 1.00 (ref) & \multirow[t]{5}{*}{0.20} \\
\hline 1 & $82 / 519(16)$ & 159/1993 (8) & $4.93(1.73$ to 14.06$)$ & 3.74 (2.40 to 5.82$)$ & \\
\hline 2 & 69/255 (27) & 153/691 (22) & 7.87 (2.75 to 22.51$)$ & $8.19(5.16$ to 13.01$)$ & \\
\hline 3 & $24 / 51(47)$ & $52 / 144(36)$ & $14.95(4.85$ to 46.03$)$ & $14.22(8.40$ to 24.09$)$ & \\
\hline 4 & 7/8 (88) & $10 / 15(67)$ & 31.01 (7.67 to 125.37$)$ & 24.37 (10.80 to 54.99$)$ & \\
\hline \multicolumn{6}{|c|}{$\begin{array}{l}\text { Serum glucose level } \\
\text { (mmol/L): }\end{array}$} \\
\hline$<4$ & $10 / 40(25)$ & $10 / 443(2)$ & 1.63 (0.65 to 4.07$)$ & 0.68 (0.33 to 1.42$)$ & \multirow[t]{5}{*}{$<0.001$} \\
\hline $4-5.99$ & $15 / 99(15)$ & $116 / 2141(5)$ & 1.00 (ref) & 1.00 (ref) & \\
\hline $6-10.99$ & $99 / 505(20)$ & 268/2254 (12) & $1.28(0.66$ to 2.46$)$ & 1.55 (1.18 to 2.04$)$ & \\
\hline $11-13.99$ & $35 / 197(18)$ & $21 / 106(20)$ & 0.88 (0.42 to 1.84$)$ & 2.11 (1.22 to 3.64$)$ & \\
\hline$\geq 14$ & $39 / 182(21)$ & $11 / 33(33)$ & 1.49 (0.72 to 3.09$)$ & 3.65 (1.84 to 7.23$)$ & \\
\hline \multicolumn{6}{|c|}{$\begin{array}{l}\text { Chronic respiratory tract } \\
\text { disease: }\end{array}$} \\
\hline No & $121 / 628(19)$ & 283/3761 (8) & 1.00 (ref) & 1.00 (ref) & \multirow[t]{2}{*}{0.67} \\
\hline Yes & $86 / 483(18)$ & $194 / 1979(10)$ & 0.99 (0.71 to 1.39 ) & 0.94 (0.75 to 1.17 ) & \\
\hline \multicolumn{6}{|c|}{ Malignant tumour: } \\
\hline No & $174 / 986(18)$ & $375 / 5207(7)$ & 1.00 (ref) & 1.00 (ref) & \multirow[t]{2}{*}{0.19} \\
\hline Yes & $34 / 126(27)$ & $97 / 521(19)$ & 1.24 (0.79 to 1.94$)$ & 1.87 (1.43 to 2.44$)$ & \\
\hline \multicolumn{6}{|c|}{ Chronic liver disease: } \\
\hline No & $194 / 1069$ (18) & $450 / 5570(8)$ & 1.00 (ref) & 1.00 (ref) & \multirow[t]{2}{*}{0.10} \\
\hline Yes & $14 / 42(33)$ & 29/172 (17) & 2.31 (1.26 to 4.25$)$ & 1.23 (0.75 to 2.01$)$ & \\
\hline \multicolumn{6}{|c|}{ Congestive heart failure: } \\
\hline No & $95 / 669(14)$ & $286 / 4924(6)$ & 1.00 (ref) & 1.00 (ref) & \multirow[t]{2}{*}{0.07} \\
\hline Yes & $114 / 444(25)$ & 190/817 (23) & $1.22(0.86$ to 1.71$)$ & 1.77 (1.41 to 2.23$)$ & \\
\hline \multicolumn{6}{|c|}{ Cerebrovascular disease: } \\
\hline No & $117 / 873(13)$ & $337 / 5263(6)$ & 1.00 (ref) & 1.00 (ref) & \multirow[t]{2}{*}{0.72} \\
\hline Yes & 89/233 (38) & $141 / 485(29)$ & 2.07 (1.47 to 2.91$)$ & $1.92(1.49$ to 2.46$)$ & \\
\hline \multicolumn{6}{|c|}{ Chronic renal disease: } \\
\hline No & $128 / 886(14)$ & $390 / 5402(7)$ & 1.00 (ref) & 1.00 (ref) & \multirow[t]{2}{*}{0.88} \\
\hline Yes & 79/222 (36) & $87 / 342(25)$ & $1.71(1.21$ to 2.44$)$ & 1.54 (1.17 to 2.03 ) & \\
\hline \multicolumn{6}{|c|}{ Current smoking: } \\
\hline No & $149 / 823(18)$ & $329 / 3822(9)$ & 1.00 (ref) & 1.00 (ref) & \multirow[t]{2}{*}{0.43} \\
\hline Yes & $31 / 236(13)$ & $105 / 1832(6)$ & 1.05 (0.66 to 1.66$)$ & 0.87 (0.65 to 1.16$)$ & \\
\hline
\end{tabular}

Row percentages may not total $100 \%$ because of missing data.

*Derived from Cox proportional hazards models after multiple imputation of missing covariate data for participants with and without diabetes mellitus. Hazard ratios larger than 1 indicate a lower mortality in reference category.

†P values for interaction between hazard ratios of death or linear trends across glucose and CRB-65 categories and diabetes status are from two sided Wald tests from interaction terms included in Cox proportional hazards models.

¥Score related to confusion, respiratory rate $>30 / \mathrm{min}$, systolic blood pressure $\leq 90 \mathrm{~mm} \mathrm{Hg}$ or diastolic blood pressure $\leq 60 \mathrm{~mm} \mathrm{Hg}$, and age $\geq 65$ years. 


\section{Figures}

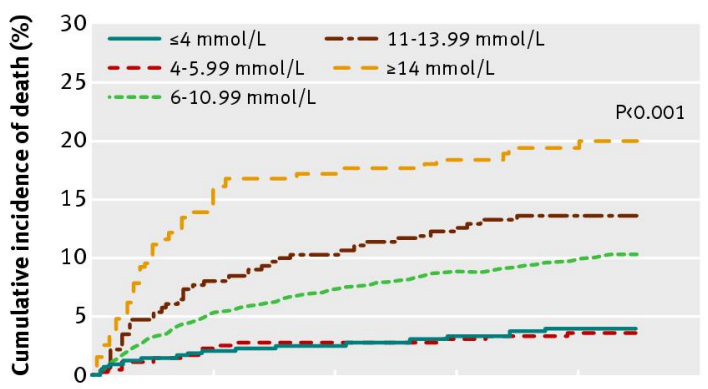

No at risk

$\leq 4 \mathrm{mmol} / \mathrm{L}$

\begin{tabular}{|c|c|c|c|c|}
\hline 484 & 473 & 471 & 470 & 467 \\
\hline \multicolumn{5}{|c|}{$4-5.99 \mathrm{mmol} / \mathrm{L}$} \\
\hline 2244 & 2200 & 2184 & 2170 & 2157 \\
\hline \multicolumn{5}{|c|}{$6-10.99 \mathrm{mmol} / \mathrm{L}$} \\
\hline 2768 & 2626 & 2563 & 2521 & 2493 \\
\hline \multicolumn{5}{|c|}{$11-13.99 \mathrm{mmol} / \mathrm{L}$} \\
\hline 303 & 279 & 272 & 266 & 262 \\
\hline \multicolumn{5}{|l|}{$\geq 14 \mathrm{mmol} / \mathrm{L}$} \\
\hline 217 & 187 & 180 & 177 & 174 \\
\hline
\end{tabular}

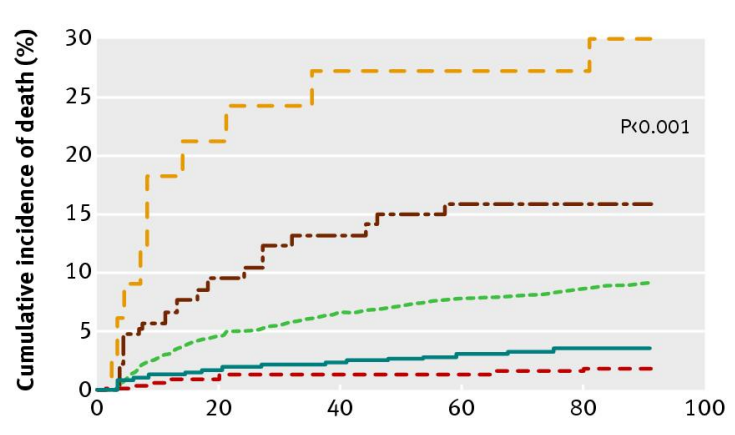

No at risk

Days after first examination

\begin{tabular}{|c|c|c|c|c|}
\hline \multicolumn{5}{|l|}{$\leq 4 \mathrm{mmol} / \mathrm{L}$} \\
\hline 443 & 437 & 437 & 437 & 435 \\
\hline \multicolumn{5}{|c|}{$4-5.99 \mathrm{mmol} / \mathrm{L}$} \\
\hline 2141 & 2104 & 2088 & 2075 & 2064 \\
\hline \multicolumn{5}{|c|}{$6-10.99 \mathrm{mmol} / \mathrm{L}$} \\
\hline 2254 & 2149 & 2103 & 2074 & 2056 \\
\hline \multicolumn{5}{|c|}{$11-13.99 \mathrm{mmol} / \mathrm{L}$} \\
\hline 106 & 96 & 92 & 89 & 89 \\
\hline \multicolumn{5}{|l|}{$\geq 14 \mathrm{mmol} / \mathrm{L}$} \\
\hline 33 & 26 & 24 & 24 & 24 \\
\hline
\end{tabular}

Fig 1 Cumulative incidence of death (\%) within 90 days in participants with community acquired pneumonia stratified by serum glucose levels on admission overall ( $n=6016)$ (top) and without diabetes $(n=5141)$ (bottom). The 875 participants with missing data for serum glucose levels on admission were not included in these calculations for patients at risk 


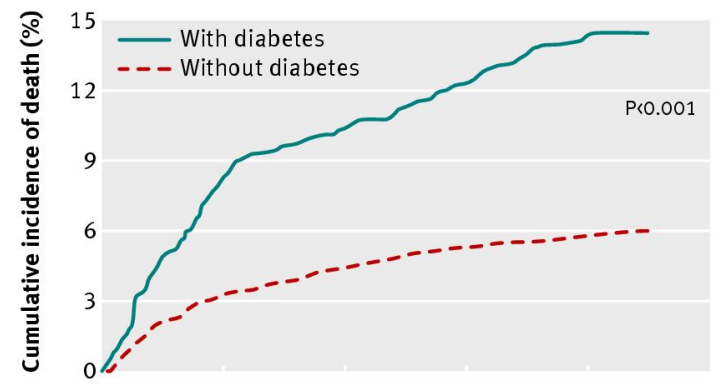

No at risk

Without diabetes

$\begin{array}{ccccc}5756 & 5570 & 5494 & 5440 & 5407 \\ \text { With diabetes } & & & & \\ 1114 & 1023 & 996 & 975 & 953\end{array}$

----- Diabetes

--- No diabetes and high serum glucose levels

- - No diabetes and normal or low serum glucose levels

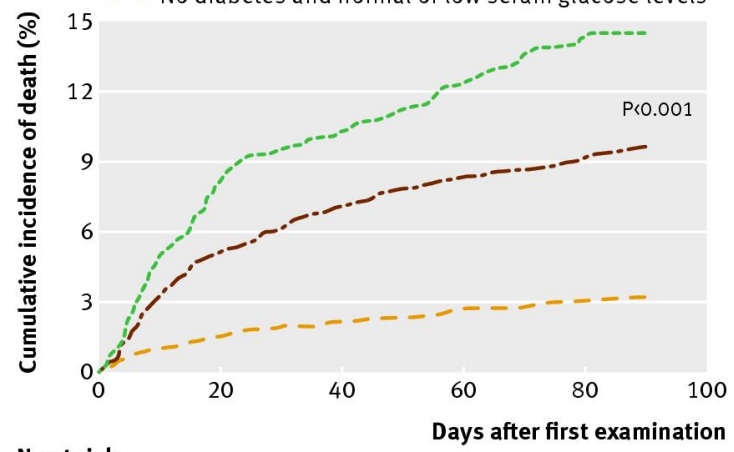

No at risk

$\begin{array}{lllll}\text { Diabetes } & & & \\ 1114 & 1023 & 996 & 975 & 953 \\ \text { No diabetes and high serum glucose levels } & \\ 2393 & 2271 & 2219 & 2187 & 2169 \\ \begin{array}{rllll}\text { No diabetes and normal or low serum glucose levels } \\ 2584 & 2541 & 2525 & 2512 & 2499\end{array}\end{array}$

Fig 2 Cumulative incidence of death (\%) within 90 days in participants with community acquired pneumonia with and without pre-existing diabetes (top) and without diabetes but stratified according to high or low serum glucose levels on admission (bottom)

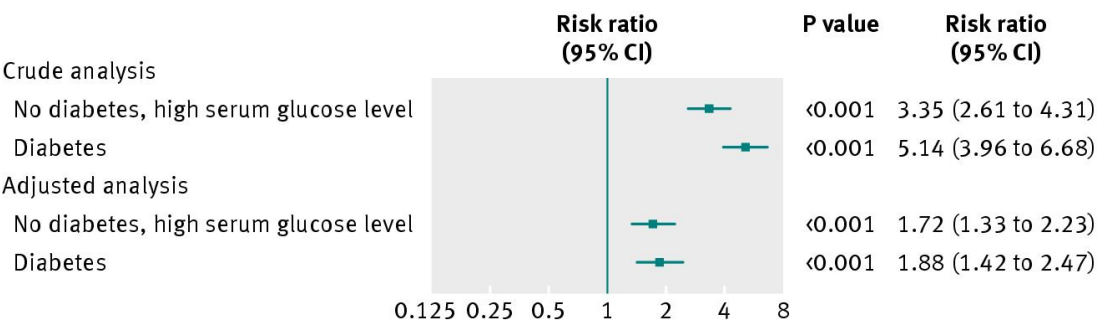

Fig 3 Crude and adjusted analyses of cohorts with the highest mortality. Results from all 6891 participants after multiple imputation 